\title{
Lightweight design of a torque plate of Z-cam drum brake for heavy duty vehicles
}

\author{
İbrahim Can Güleryüz ${ }^{1 *}$, Barış Yılmaz ${ }^{2}$
}

0000-0002-2002-6684, 0000-0003-2439-5636

\author{
${ }^{1}$ Product Design Engineer, Ege Fren Sanayii ve Ticaret A.S., Izmir/Turkey \\ ${ }^{2}$ Product Design Chief, Ege Fren Sanayii ve Ticaret A.S., Izmir/Turkey
}

\begin{abstract}
Reducing vehicle weight without compromising performance becomes an area which is important to improve fuel economy and reduce vehicle emissions. The possibility of reducing unsprung mass in a vehicle has led to many investigations of weight optimization studies of axle and wheel-end components. Therefore, structural design of a torque plate, which is one of the main parts of a Z-cam drum brake used in heavy-duty vehicles, is carried out by using topology optimization and finite element analyses. Firstly, finite element analysis of the original torque plate is conducted to determine critical stress levels and locations. Secondly, topology optimization is carried out on the original torque plate for specified loading conditions. Taking redundant volume and manufacturability constraints into account a new torque plate design is composed. Finally, finite element analysis is repeated to verify the final design. A significant decrease in stress level is accompanied by considerable reduction in casting and machined part masses by $11.9 \%$ and $12.2 \%$ respectively.
\end{abstract}

Keywords: Torque plate, topology optimization, finite element analysis, Z-cam drum brake, heavy duty vehicles.

\section{* Corresponding author \\ İbrahim Can Güleryüz \\ can.guleryuz@egefren.com.tr}

Address: Ege Fren Sanayii ve Ticaret A.S 7405/2 Sokak No: 435060

Pınarbaşı - İzmir

Tel: +902323973736

Fax: +902324790208

Research Article

Manuscript Received 20.05.2019

Revised 15.06.2019

Accepted 17.06.2019

Doi: 10.30939/ijastech..568059

\section{Introduction}

The brake system is one of the most critical subsystems to ensure the safety of a vehicle on road. It is designed to slow down the vehicle to maintain its speed during downhill operation and to hold the vehicle stationary after it has come to a complete stop [1]. For the purpose of braking, kinetic energy of the vehicle is converted into heat energy due to friction between the rotor, also called a brake drum or brake disc and the linings, which are the friction elements [2].

There are two main types of friction brake that have been in common use on road vehicles for many years. A disc brake works by pressing 'pads' of friction material against each side of a rotating disc, while in a drum brake the brake linings mounted on 'shoes' expand outwards against the inner surface of a rotating drum [3]. New passenger vehicles are now fitted exclusively with disk brakes at the front, and there is an increasing trend towards disk brakes for the rear wheels as well [4]. Over the past 20 years, this trend has also applied to Commercial Vehicles in Europe and to a lesser extent in North America and the rest of the world.

In the past decade, a tendency showed that the drum type foundation brakes were replaced by disc brakes in some vehicle types [5]. However, drum brakes such as S-cam, Zcam and wedge type brakes are still more widely used than disc brakes for on- and off-highway truck and trailer linehaul, vocational and military applications in many parts of the world outside Europe.

Reducing vehicle weight without compromising performance is the primary objective of many automotive manufacturers to improve fuel economy and reduce vehicle emissions [6]. The possibility of reducing the unsprung mass in a vehicle has led to many investigations about weight optimization studies of axle and wheel-end components like axle beam, differential housing, lower and upper wishbones, foundation brake parts, brake disc and drum. Therefore, the focus and objective of this study is the weight optimization 
of a torque plate which is one of the main parts of Z-cam drum brake used in heavy duty vehicles.

There are many studies in current literature about weight optimization of axle and wheel-end components.

Sergent et al., performed an optimization study of a fourpiston caliper. By using topology optimization method two optimized designs were obtained. Both designs offered considerable reduction of caliper mass, by $19 \%$ and $28 \%$, respectively [7].

Mathur and Kurna, studied axle beam weight optimization. Beam section parameters like flange height, width etc. were chosen to be optimized using shape optimization algorithm and the analysis was conducted under severe braking and turning conditions. The result was about $9 \mathrm{~kg}$ lighter axle (initial weight of axle beam $50 \mathrm{~kg}$ ) optimized for lower load vehicles [8].

Topac and Atak, conducted design of experiments (DOE) based optimization study to improve both weight and stress concentration of front axle beam that used in heavy commercial vehicles. As a result of this study, maximum stress values on the critical section of axle beam were reduced to $25 \%$ and axle beam weight was optimized about $10 \%$ in comparison with the commercial axle beams that are used in local market within same loading capacity [9].

Topac et al., studied a multi-objective optimization process that was also carried out with Design of ExperimentsResponse Surface Methodology (DOE-RSM). In finite element analyses, effects of various driving conditions were considered. It was determined that the new design obtained from the optimization is about $1.8 \mathrm{~kg}$ lighter than the initial design. Results also showed that, it is possible to reduce the stress concentration at critical regions about $18 \%$ and $36 \%$ respectively, in comparison with the initial design [10].

Topac et al., carried out structural design of the lower wishbone used in the independent front suspension of a military vehicle by using topology optimization. At the end of the study, it was obtained that new design is $19.25 \%$ lighter than original design [11].

To the best of our knowledge, the only published study that has addressed weight optimization problem of a backplate is that of Yucel et al. [12]. They conducted topology optimization of a back-plate of S-cam drum brake that is widely used in heavy duty vehicles. Analytical calculation was carried out to obtain S-cam brake factor and operating loads acting on back-plate. Regarding the calculation results, finite element analyses of current back-plate design were performed to figure out critical stress regions on the backplate. After that, topology optimization was applied to the primary design and the redundant volume on the primary design was determined. Final back-plate design was composed according to casting and machining methods. Finite element analyses were applied to the final design for the verification purposes. As a result of the study, the weight of casting back-plate was decreased about $18.59 \%$ without any reduction on strength in comparison with the original de-

\section{sign.}

Although the abovementioned investigations are related with the weight optimization of axle and wheel-end parts which are unsprung mass in the vehicle, there are some studies about improving and optimizing performance parameters of drum brakes.

Zhang et al., investigated a multi-objective optimization model of drum brake. For the purpose of maximizing the braking efficiency, minimizing both of the volume and temperature rise, they present a differential evolution cellular multi-objective genetic algorithm (DECell) for tackling this problem. Results showed that, DECell is an effective algorithm; it can find much more and better solutions stably compared with one of the popular multi-objective algorithms of NSGA-II [13].

Sayim and Zhang, investigated the effects of dimensional properties on the brake factor (BF) of an S-cam foundation brake. The response surface method (RSM) was used to identify the BF-reduced combination of dimensions within theoretical results. For the validation of relative improvement of BF, a new test procedure was introduced and a new test rig was built. One sample was tested with nominal dimensions as assembled on the vehicles on the market. Another sample was produced in accordance with modified dimensions obtained from RSM analysis. It was shown from the test results that, a relative reduction about $22.93 \%$ on BF was obtained, creating a more stable drum brake with a friction level sensitivity characteristic more like a disc brake [5].

Ragothaman et al., conducted finite element analyses of S-cam drum brake parts of shaft and torque plate for the alternative materials. As an alternative material of C55 Steel (medium carbon steel) instead of mild steel for S-cam shaft and 50CrV4 (chromium vanadium alloy) for torque plate as a substitute for spheroidal cast iron were chosen. It was shown from the simulation results that total deformation, equivalent (von-Mises) stress and equivalent elastic strain values of both alternative material selections are lesser compared with conventional materials [14].

It can be seen from the literature review that the design of axle and wheel-end parts is contributing unnecessary weight to the unsprung mass due to over-design. Hence, weight optimization is required to reduce the unsprung mass of the vehicle by using computer aided engineering tools.

Based on a foregoing statement, this paper establishes a topology optimization study on a torque plate of the Z-cam drum brake widely used in heavy duty vehicles in Europe, which aims to maximise the mechanical strength, minimise the weight and the manufacturing costs of the torque plate.

The rest of the paper is organized as follows: Section 2 describes working principle and usage of Z-cam drum brake and its components. Section 3 presents finite element analysis of the original torque plate design to determine critical stress levels and locations on the original design 
used in Z-cam drum brakes; Section 4 describes topology optimization that is applied to the original design for selected load cases. According to topology optimization results and manufacturability constraints a new back-plate design is proposed. Finally, finite element analyses are conducted to verify the optimized torque plate design. Section 5 presents finite element and topology optimization results. This paper concludes with a summary in Section 6 .

\section{Working principle of $\mathrm{Z}$-cam drum brake}

Before starting a finite element analysis, it is important to understand the usage and working principle of the Z-cam drum brake and its components. The Z-cam i.e. SAC brake is one of the drum brakes that is widely used in heavy duty vehicles in Europe. A Z-cam foundation brake mainly consists of lever, shaft, struts, leading and trailing shoes, Cspring, tappet heads, torque plate, dust shield, bracket and parts of automatic adjustment mechanism as shown in Figure 1 . Both shoes are mounted on a torque plate, which is firmly bolted on the vehicle's axle flange or steering knuckle also termed 'back-plate', 'anchor plate', 'spider' or 'reaction frame' [3].

Compressed air in the brake chamber generates a mechanical force that is transmitted to the brake shoes through tappet heads, struts, shaft and lever respectively. Shoes slide along their abutments at one end, while they are mechanically actuated by tappet heads at another end. The travel of the tappet heads increases due to the wear of the brake linings or the heat-related expansion of the brake drum as a consequence of braking operation. An automatic adjustment mechanism is used to compensate for increases in this gap because the chamber force transmitted to the brake shoes decreases rapidly, when the brake chamber stroke exceeds a certain limit. Depending on the direction of rotation of the drum and shoes, the shoe where the drum and shoe rotate in the same direction is known as the leading shoe and the trailing shoe is where the drum and shoe rotate in the opposite direction) in Figure 2 [15].

\section{Finite element analysis of original torque plate}

For the finite element analysis of original torque plate, a 3D model (Figure 3-a), which is modelled with Catia V5R19, is imported into ANSYS Mechanical 19.2. Multilinear GGG50 i.e. EN-GJS-500 (spheroidal cast iron) is assigned to the torque plate using material properties which are obtained experimentally from the tensile test of spheroidal cast iron and are shown in Table 1 and Figure 4 below. For the finite element mesh, tetrahedral elements are used and $3 \mathrm{~mm}$ element size is applied to all torque plate surfaces with performing mesh refinement. It consists of 329180 nodes and 191861 elements as shown in Figure 3-b. Minimum bounding box dimensions of the original torque plate are $379 \mathrm{~mm}$ x $258 \mathrm{~mm}$ x $95 \mathrm{~mm}$.

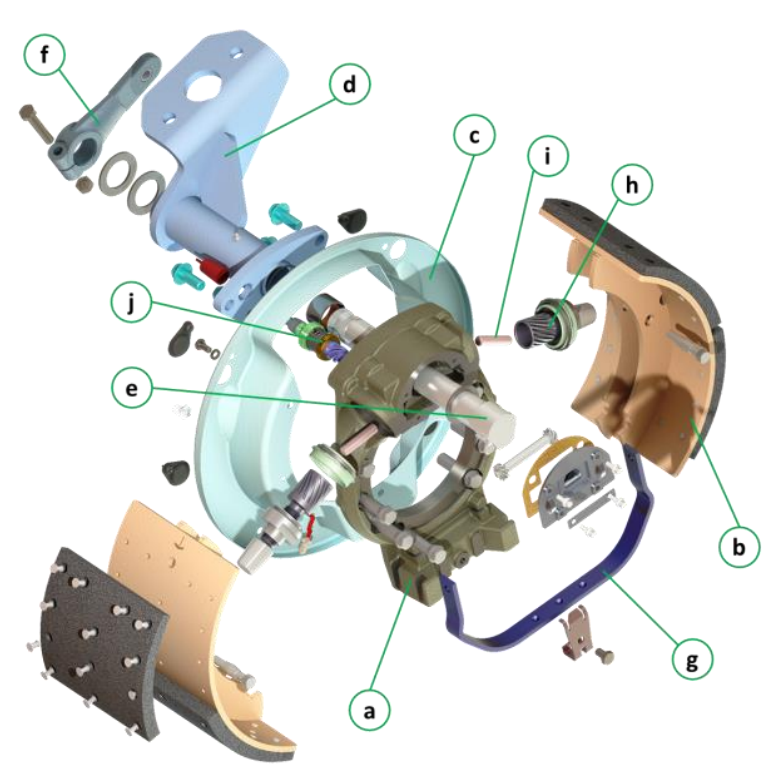

Figure 1. Z-cam drum brake components: (a) Torque plate, (b) Shoes, (c) Dust shield, (d) Bracket, (e) Shaft, (f) Lever, (g) C-spring, (h) Tappet heads, (i) Struts and (j) Parts of automatic adjustment mechanism.

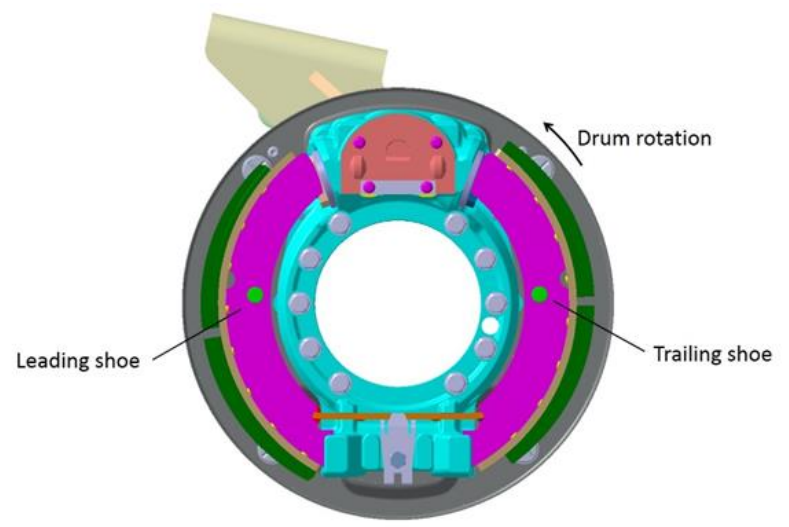

Figure 2. Leading and trailing shoe definition of drum brake.
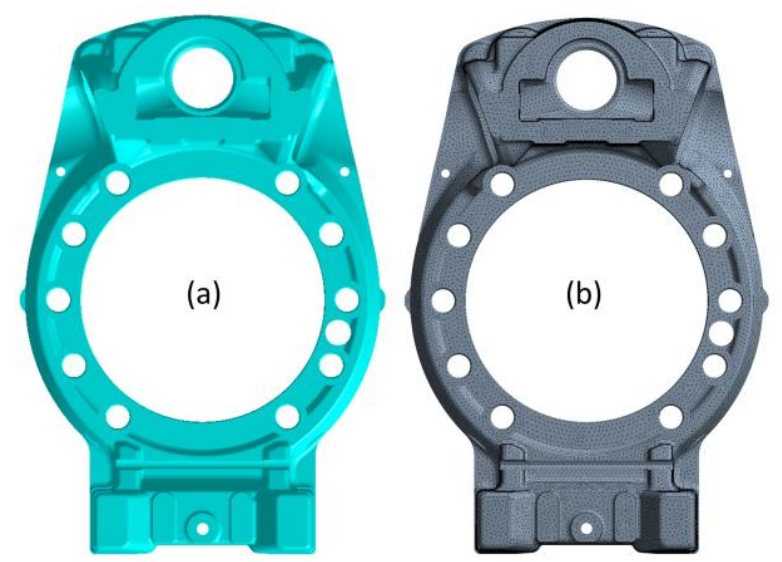

Figure 3. (a) 3D model of original torque plate design, (b) Finite element model of original torque plate design. 
$F_{P 2} . r_{P 2}-F_{T 2} . r_{T 2}-F_{N 2} . r_{N 2}=0$

Table 1. Material properties of GGG50.

\begin{tabular}{lc}
\hline Material properties of GGG50 & \\
\hline Young's modulus [GPa] & 170 \\
Poisson's ratio [-] & 0.29 \\
Yield strength [MPa] & 360 \\
Density $\left[\mathrm{kg} / \mathrm{m}^{3}\right]$ & 7300 \\
\hline
\end{tabular}

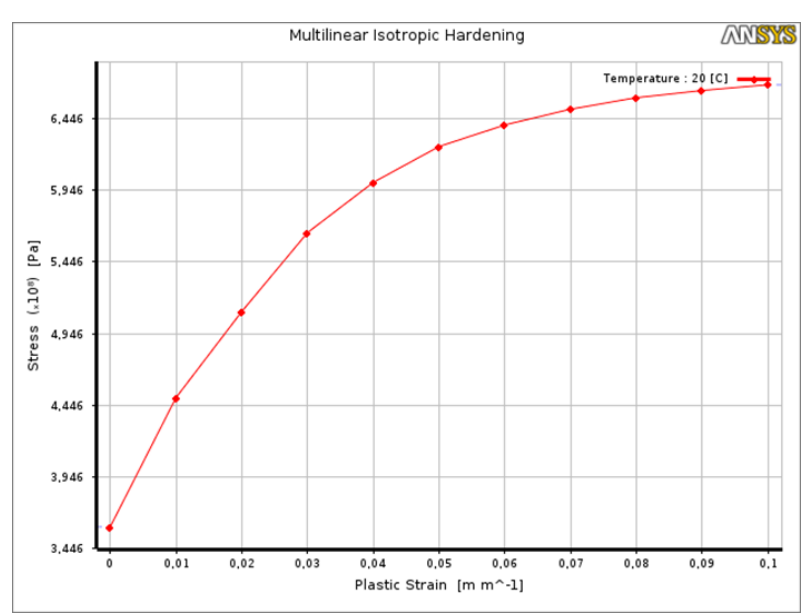

Figure 4. Multilinear isotropic hardening curve of GGG50.

The original torque plate has been designed for maximum $20 \mathrm{kNm}$ braking torque $\left(\mathrm{T}_{\mathrm{b}}\right)$. For this condition, the reaction forces which occur at the shaft bearing surface and at both abutment ends of the leading and trailing shoes due to braking operation, are applied to the torque plate in the 1st step of the analysis (Figure 6-a). Vector analysis is performed to obtain these reaction forces acting on leading and trailing shoes. The calculation is mentioned below, using a friction coefficient $\mu=0.37$, which is assumed for the Z-cam drum brake lining. Figure 5 shows the basic mechanics of the drum brake used in vector analysis, which are composed of tangential $\mathrm{F}_{\mathrm{T} 1-2}$ and normal forces $\mathrm{F}_{\mathrm{N} 1-2}$, abutment-end forces $\mathrm{F}_{\mathrm{A} 1-2}$ and piston forces $\mathrm{F}_{\mathrm{P} 1-2}$. The calculation starts by considering the total friction drag generated by brake lining on each brake shoe as it is forced against the rotating drum. It is necessary to analyse each brake shoe individually and then combine the two to obtain total brake torque [3].

Resolving forces horizontally and vertically, force balance can be written for leading and trailing shoes as,

$F_{N 1 x}-F_{P 1 x}-F_{A 1 x}=0$

$F_{A l y}-F_{T 1 y}-F_{P l y}=0$

$F_{P 2 x}+F_{A 2 x}-F_{N 2 x}=0$

$F_{A 2 y}+F_{T 2 y}-F_{P 2 y}=0$

Applying moments about Q1 and Q2 for leading and trailing shoes as,

$F_{N 1} . r_{N 1}-F_{T 1} . r_{T 1}-F_{P 1} . r_{P 1}=0$ where,

$F_{T 1-2}=T_{b} /\left(2 . r_{\text {drum }}\right)$

$F_{N 1-2}=F_{T I-2} / \mu$

The calculated reaction forces are summarized in Table 2. Besides these, a fixed support boundary condition is defined to the axle mounting holes on the torque plate.

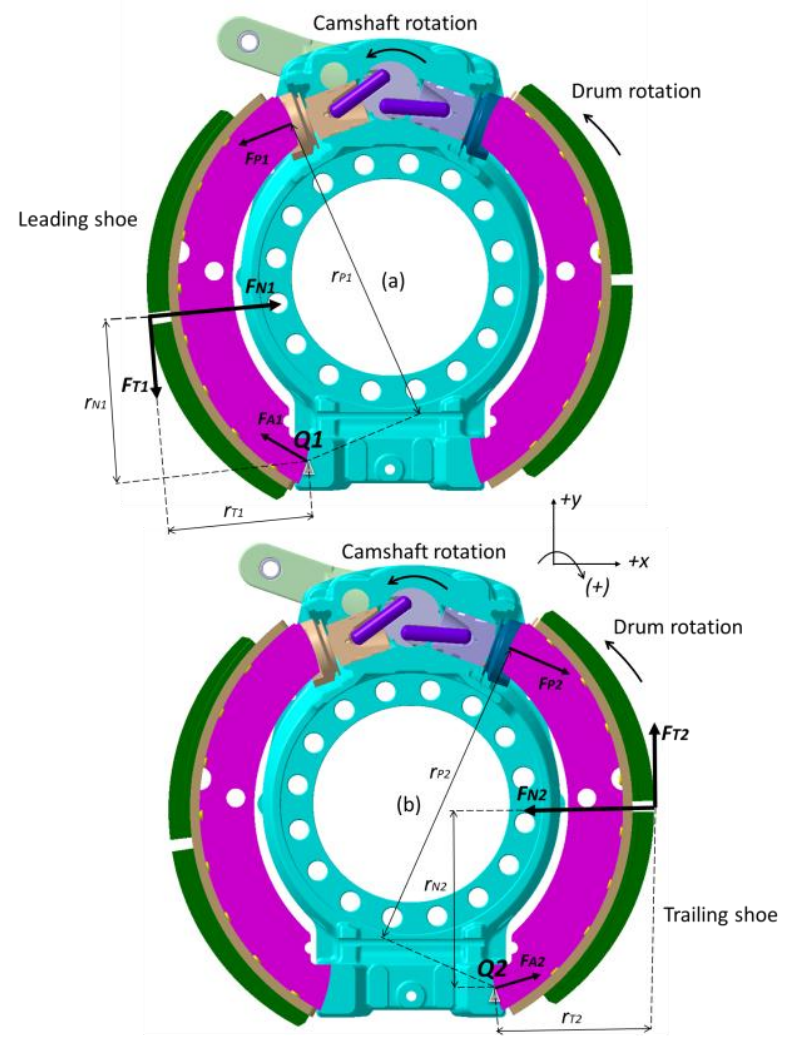

Figure 5. Forces acting forces on the shoes of Z-cam brake: (a) Leading side, (b) Trailing side.

The most critical loading scenario occurs during braking in a bumpy road. Therefore, in addition to the operating forces, in the 2nd step of the analysis, vibrational loads, which are transferred from the brake chamber bracket to the torque plate, are applied. Vibrational loads occur due to the acceleration of the mass of parts such as bracket, brake chamber, shaft and lever, which are connected to the torque plate. For this reason, remote forces are applied to the bracket mounting surface and holes. One remote force is defined to simulate the vibrational load of brake chamber on the centre of gravity of the component. Another remote force is added for the vibrational load of the other components (see in Figure 6-b). Regarding to our field measurements, the magnitude of the maximum acceleration due to 
vibration is $30 \mathrm{~g}$ ( $\mathrm{g}=$ gravitational acceleration) as a combination of horizontal and vertical components. The magnitude of transverse acceleration is significantly lower in comparison with the other components of acceleration. Thus, transverse acceleration is neglected in the torque plate analysis. In the 2nd step of the analysis, magnitude and direction of vibrational loads are calculated by considering the accelerations in $30 \mathrm{~g}$.

In addition to these 2 steps, 8 more steps are defined to the analysis to simulate other mounting positions of torque plate on the axle flange or steering knuckle. For this purpose, direction of vibrational loads is rotated with an increment of $10^{\circ}$ for each step of analysis as shown in Figure 6-c.

Table 2. Reaction forces acting on torque plate.

\begin{tabular}{lc}
\hline Reaction forces [N] & \\
\hline Shaft bearing force-leading side $\left(\mathrm{F}_{\mathrm{P} 1}\right)$ & 48864 \\
Shaft bearing force-trailing side $\left(\mathrm{FP}_{\mathrm{P}}\right)$ & 87344 \\
Abutment-end force-leading $\left(\mathrm{F}_{\mathrm{A} 1}\right)$ & 117910 \\
Abutment-end force-trailing $\left(\mathrm{F}_{\mathrm{A} 2}\right)$ & 35175 \\
\hline
\end{tabular}

Total deformation, von-Mises and Maximum Principal Stress plots are obtained for the original torque plate design as shown in the Figure 7. Regarding analysis results, 5 locations (see Figure 7-d) are determined as critical stress regions (hotspot locations) on the torque plate. Stress values of this locations are summarized in Table 3.

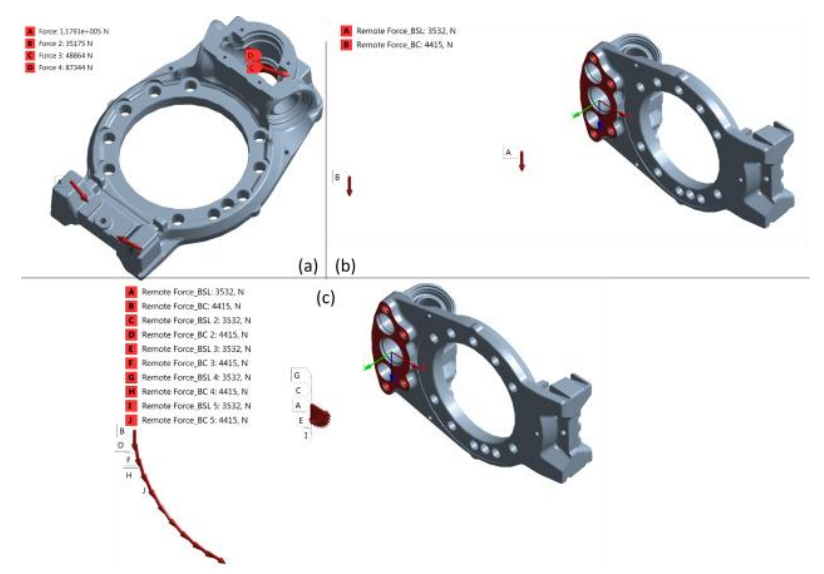

Figure 6. Boundary conditions (a) 1st step, (b) 2nd step, (c) Other steps.

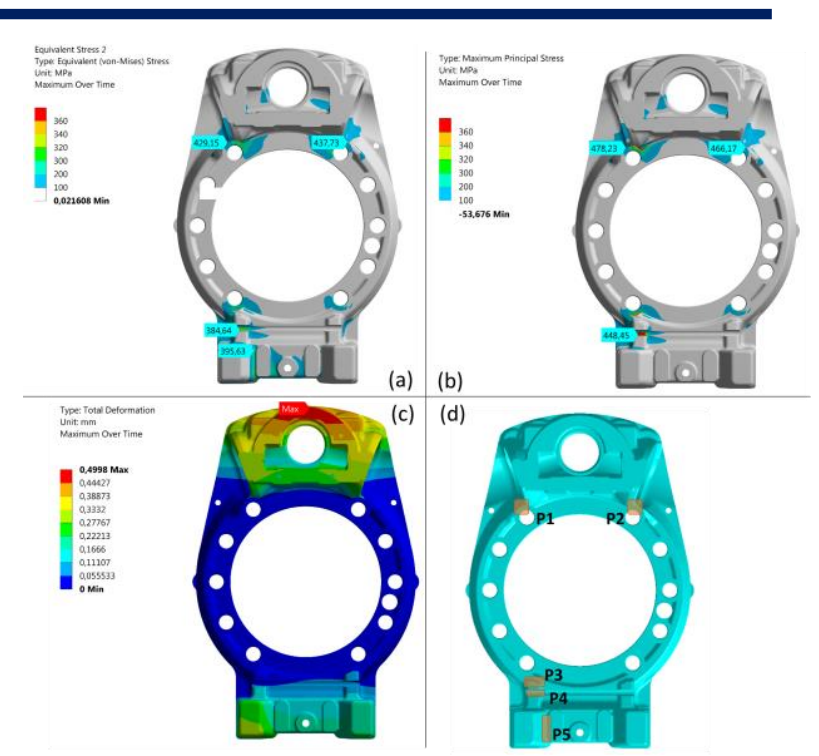

Figure 7. Analysis results of original design: (a) von-Mises Stress, (b) Maximum Principal Stress, (c) Total deformation, (d) Hotspot stress locations.

\section{Topology optimization, re-modelling and verifica- tion analysis}

In this study, weight reduction investigation of torque plate of Z-cam drum brake is conducted by using the topology optimization method as one of the structural optimization methods. Topology optimization combines finite element analysis with mathematical optimization algorithms. Topology optimization aims to find the best use of material within a given design space, while fulfilling requirements on stiffness, displacement, eigenvalues, etc. This approach uses iterative methods for optimizing the distribution of isotropic material in a structure subjected to a known specified load case [16]. In a typical topology optimization problem, the goal is stated in terms of a maximum stiffness (minimum compliance) approach. In this formulation, the aim is to distribute a given amount of material in a certain domain, so that the stiffness of the resulting structure is maximized (the compliance or energy of deformation is minimized) for a given load case [17]. Further background of this technique is given by Bakhtiary et al. [18], Bendsøe and Sigmund [19]. The approach used for topology optimization of structural components is given in Figure 8 below [16]. 
and finite element analyses are conducted by considering the casting and machining processes. It is necessary to repeat this process several times to improve stress values showed in critical stress regions and to create the final, optimized design. The design modification steps, which are conducted from the original design to the final design of torque plate, are summarized in Figure 11.

Figure 8. Topology optimization approach to design of structural parts and components.

For the purpose of topology optimization, firstly the finite element analysis of the original torque plate is performed by applying $3 \mathrm{~mm}$ body sizing to the torque plate under the boundary conditions whose details are mentioned in previous section. After that, the topology optimization stage begins by creating the relationship between finite element and topology optimization modules in ANSYS 19.2. Topology optimization is performed by using default optimization algorithm of ANSYS. The parameters for optimization are as follows:

- Designable region: This is the maximum available volume into which material will be added or removed. For the torque plate, designable region is indicated in Figure 9-a in blue colour.

- Non-designable (Exclusion) region: This groups the areas of the model that cannot be modified. For the torque plate, all machined surfaces (abutment-ends, C-spring channel, all mounting and fixing surfaces and holes) are defined as exclusion region that are shown in Figure 9-a in red colour.

- Boundary conditions: All the boundary conditions were extracted from the finite element model previously built in Section 3.

- Optimization constraints: Pull-out direction and minimum member size a value of $7 \mathrm{~mm}$ is defined by manufacturing constraints as shown in Figure 9-b.

- Optimization objective: The aim is to optimize the torque plate for minimum mass for the given stiffness (stresses and deflection). Thus, the optimization objective is minimizing the part weight by $30 \%$.

For each element is given a density: the element with ' 0 ' density represents a void i.e. removed element and the element with a density of ' 1 ' is a solid (full) i.e. retained element. Therefore, any zone of the model with elements having very low densities should not be included in the final design of the component. The final decision which volumes to keep is left to the discretion of the designer [16].

The output of the topology optimization is the topology density. In Figure 10 is shown a plot of all elements with densities of 0.4 and above. The contour of the designable volume can be also seen. As expected, the obtained shape is very non-symmetrical due to loading conditions.

This 'raw' optimized solution (Figure 10) is exported from ANSYS topology optimization module to Catia V5R19 to achieve the final, optimized design of torque plate. For this purpose, several further design modifications

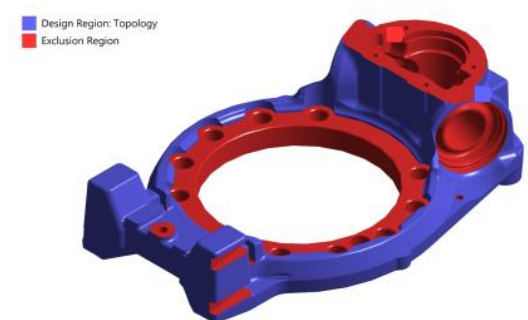

(a)

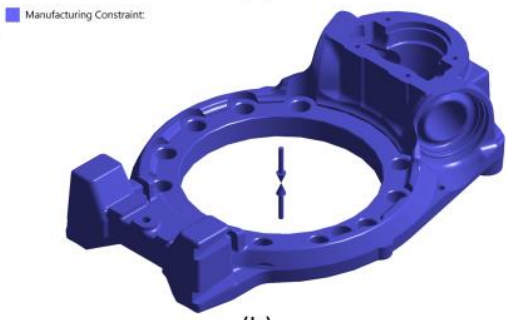

(b)

Figure 9. Topology parameters of original torque plate design (a) Design and exclusion regions, (b) Pull-out direction definition.

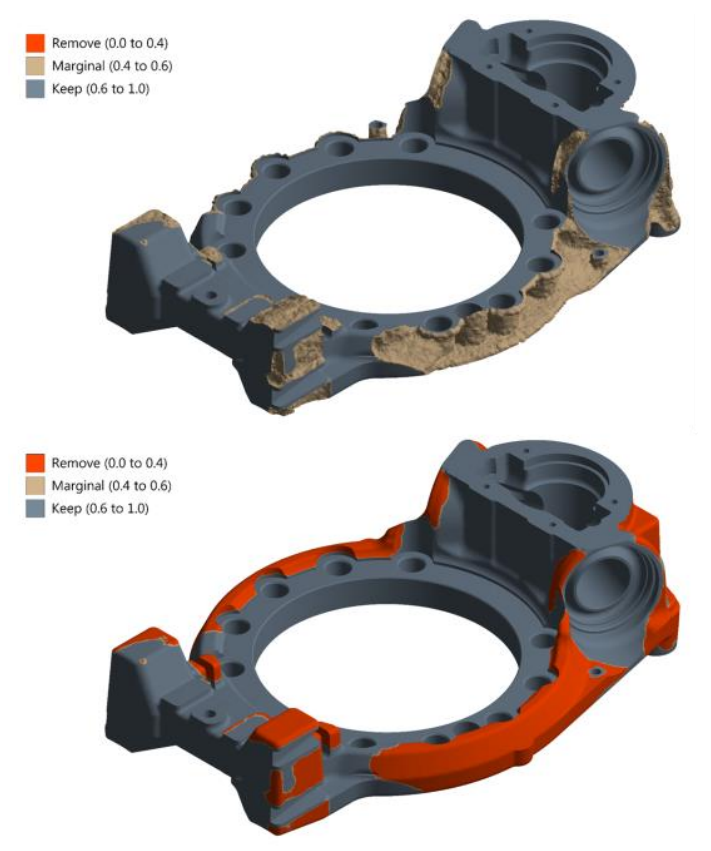

Figure 10. Topology density results of initial torque plate design. 


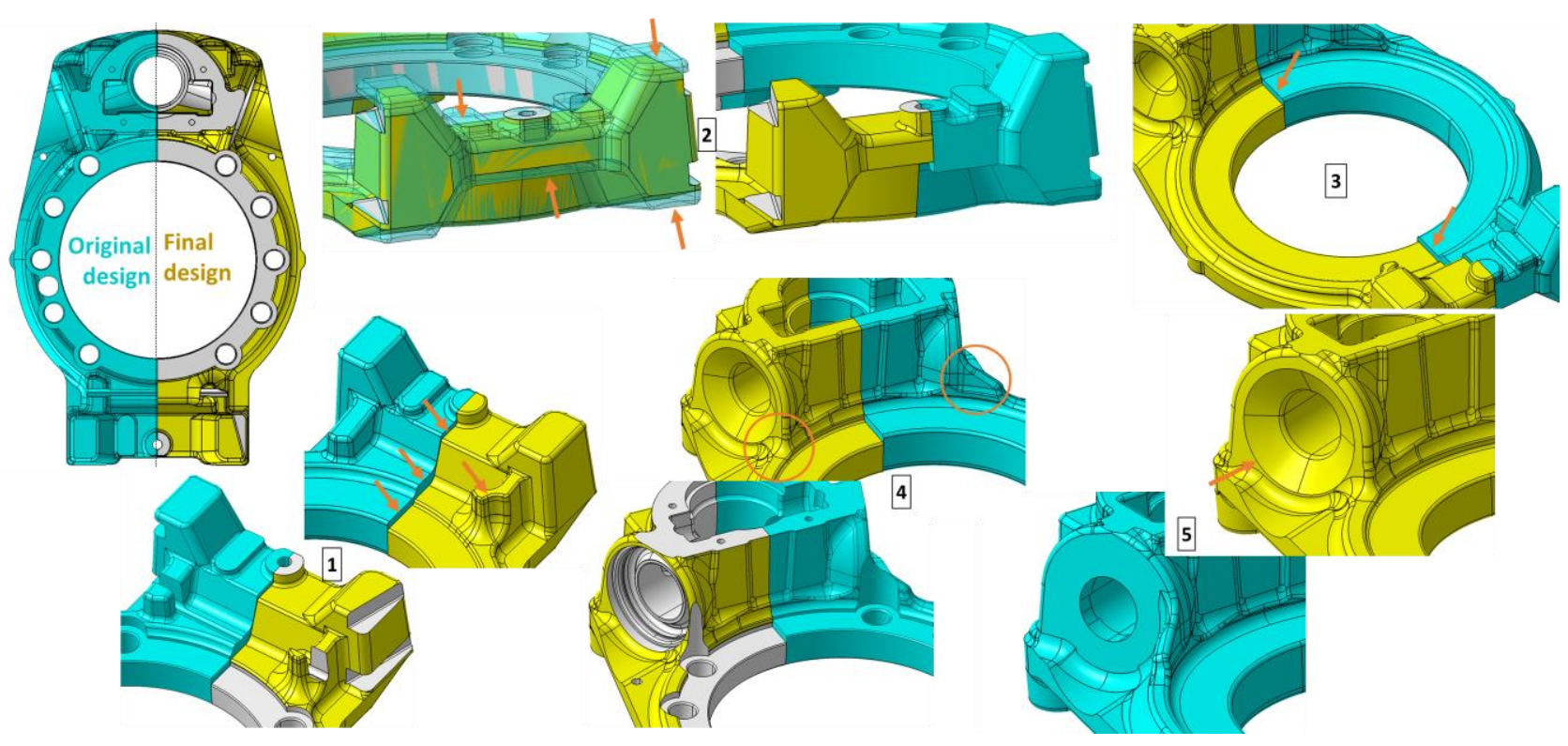

Figure 11. Design modifications.

To verify the final design, a finite element analysis, whose details are shared in Section 3, is conducted. Total deformation, von-Mises and Maximum Principal Stress plots of the optimized torque plate design are given in Figure 12 below.

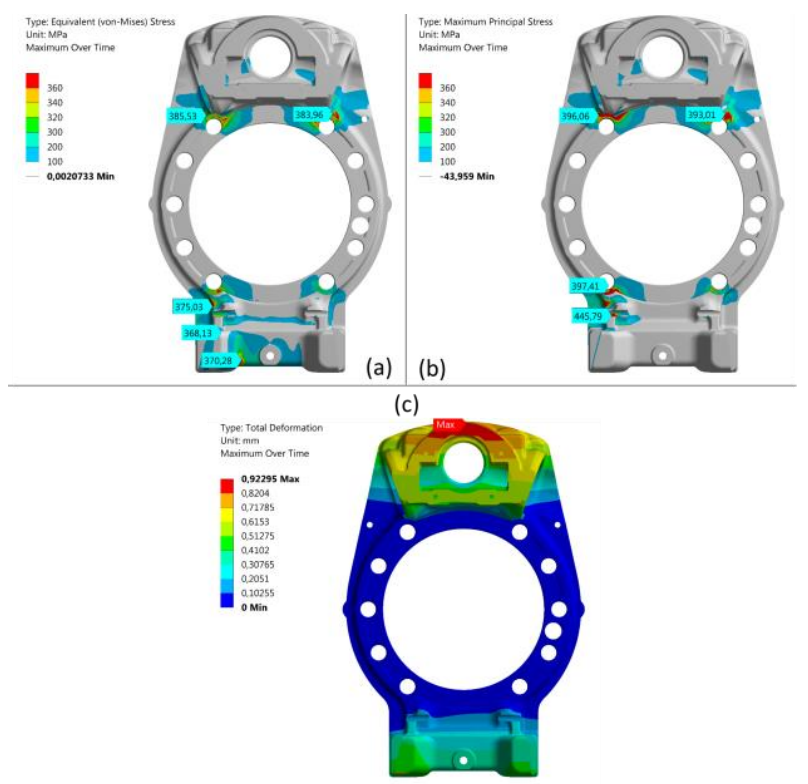

Figure 12. Analysis results of final design (a) von-Mises Stress, (b) Maximum Principal Stress, (c) Total deformation.

\section{Results and discussion}

Following the previous considerations, Figure 13 shows the two torque plate designs as a part of the foundation brake assembly. Initially, these two designs look different, but with a more careful examination, Figure 11 shows the differences step by step. Some common features especially machined surfaces like abutment-ends, C-spring channel, all mounting and fixing surfaces and holes remain unchanged in the new design.
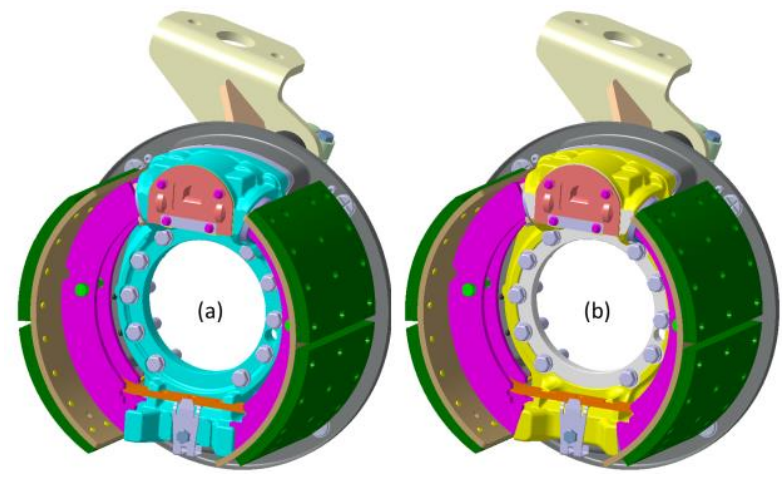

Figure 13. Original and optimized torque plate design within Z-cam brake assembly (a) Original design, (b) Final, optimized design.

Table 3 compares the finite element analysis results of both torque plate designs. When von Mises Stress results are compared, it can be seen that stress values on hotspot locations (P1, P2, P4 and P5) of final design decrease sig- 
nificantly in range of $4.3-12.3 \%$ apart from the location indicated with $\mathrm{P} 3$, on which the maximum stress value increases slightly by $1.4 \%$ in comparison with original design. This increment is acceptable when compared with other stress values obtained from hotspot locations of the original torque plate design. It can be seen from the maximum Principal stress results that the stress concentration of the final design is improved on hotspot locations (P1, P2, P4 and P5) of final design decrease significantly in range of $0.6-$ $17.2 \%$ apart from the location indicated with $\mathrm{P} 3$, on which the maximum stress value increases slightly by $4.9 \%$.

Original torque plate design provides fatigue life of minimum 100.000 cycles under $20 \mathrm{kNm}$ braking torque. For this loading scenario, infinite fatigue life is not required. Thus, it is an expected result that the stress values on hot spot locations are higher than material yield strength. Maximum von-Mises and Principle Stress values of original torque plate are calculated as 437.7 $\mathrm{MPa}$ and 478.2 $\mathrm{MPa}$ respectively. Therefore, acceptable stress limits for final design are defined as $437 \mathrm{MPa}$ for von-Mises Stress and $478 \mathrm{MPa}$ for maximum Principle Stress on all hotspot locations. According to this criteria stress results of final design are acceptable.

Maximum deformations are increased by $66.6 \%$ and $85.0 \%$ respectively for the 1 st and last time steps. In response to this, maximum deformation at the 1st time step corresponds from $0.311 \mathrm{~mm}$ to $0.518 \mathrm{~mm}$. The difference is low, therefore it is supposed that, this increment on the total deformation will not affect the brake operation and performance negatively. However, this claim should be validated by experimental investigation by taking into consideration the impact on other factors such as noise. On the other hand, maximum deformation over time is increased $85.0 \%$. It is also supposed that, this is acceptable, because this deformation value will not cause interference between Z-cam drum brake components. In addition, the torque plate will not be sustained to combination of vibrational and operational loads as much as singular operational or vibrational loads during its service life.

Table 3. Analysis results of original and final designs.

\begin{tabular}{|c|c|c|c|c|c|c|c|c|c|c|c|}
\hline \multirow{2}{*}{$\begin{array}{l}\text { Maximum Over } \\
\text { Time }\end{array}$} & \multicolumn{5}{|c|}{ von-Mises Stress [MPa] } & \multicolumn{4}{|c|}{ Maximum Principle Stress [MPa] } & \multicolumn{2}{|c|}{$\begin{array}{c}\text { Total Deformation } \\
{[\mathrm{mm}]}\end{array}$} \\
\hline & $\mathrm{P} 1$ & $\mathrm{P} 2$ & P3 & P4 & P5 & P1 & $\mathrm{P} 2$ & P3 & P4 & 1st step & $\begin{array}{l}\text { Max. Over } \\
\text { Time }\end{array}$ \\
\hline Original design & 429.2 & 437.7 & 369.8 & 384.6 & 395.6 & 478.2 & 466.2 & 378.8 & 448.5 & 0.311 & 0.499 \\
\hline Final design & 385.5 & 384.0 & 375.0 & 368.1 & 370.3 & 396.1 & 393.0 & 397.4 & 445.8 & 0.518 & 0.923 \\
\hline Change [\%] & -10.2 & -12.3 & +1.4 & -4.3 & -6.4 & -17.2 & -15.4 & +4.9 & -0.6 & +66.6 & +85.0 \\
\hline
\end{tabular}

When examining casting and machining part weights of both designs, the final design offers a considerable weight reduction, especially for the casting part weight which is reduced by $11.9 \%$ to $1.877 \mathrm{~kg}$. Additionally, the machining part weight decreases by $1.497 \mathrm{~kg}$ which is an improvement of $12.2 \%$ as shown in Table 4 below. It can also be concluded that the optimized design meets all manufacturing constraints without any reduction on mechanical strength of the torque plate.

Table 4. Weight comparison.

\begin{tabular}{lcc}
\hline & $\begin{array}{c}\text { Casting weight } \\
{[\mathrm{kg}]}\end{array}$ & $\begin{array}{c}\text { Machining weight } \\
{[\mathrm{kg}]}\end{array}$ \\
\hline Original design & 15.752 & 12.235 \\
Final design & 13.875 & 10.738 \\
\hline \multirow{2}{*}{ Weight reduction } & 1.877 & 1.497 \\
& {$[11.9 \%]$} & {$[12.2 \%]$} \\
\hline
\end{tabular}

\section{Conclusions}

As the technology develops, reducing the vehicle weight without compromising performance becomes a popular area, which allows researchers to improve fuel economy and reduce vehicle emissions. The possibility of reducing the unsprung mass in a vehicle has led to many investigations of weight optimization studies of axle and wheel-end components.

For this reason, firstly, finite element analysis of the original torque plate design of a Z-cam drum brake is conducted to figure out critical stress levels and locations. Secondly, the topology optimization was applied to the original torque plate design for specified loading conditions. Using topology optimization results and manufacturability constraints, a new backplate design is composed. At the end of the study, finite element analysis is performed to final design to verify the design.

As the final outcome of the study, when the analysis results of both design are compared, it can be seen that the stress concentration decreases significantly within a considerable reduction in the casting and machined part masses of final design by $11.9 \%$ and $12.2 \%$ respectively.

Further research should include the weight optimization of other Z-cam brake components of shoes and brackets that compose the majority of the total drum brake mass. In this way, considerable decrease in unsprung mass on wheelend could be achieved. 


\section{Acknowledgement}

The author(s) would like to acknowledge and thank Ege Fren Sanayii ve Ticaret A.S. for the supporting this research. Special thanks to Richard Thompson C.Eng. for contribution in recommendations that greatly improved the paper.

\section{References}

[1] Limpert, R. Brake design and safety, SAE, 1992.

[2] Güleryüz, İ. C. Modelling, Analysis and Experimental Verification of Pneumatic Brake System. MSc Thesis, Izmir Katip Celebi University, TR, 2017.

[3] Day, A. J. Braking of road vehicles. Butterworth-Heinemann, 2014.

[4] Reif, K. Brakes, Brake control and driver assistance systems. Weisbaden, Germany, Springer Vieweg, 2014.

[5] Sayim, I. and Zhang, D. Optimization of the brake factor for an S-Cam foundation brake using RSM/Optimizacija zavornega faktorja pri bobnastih zavorah z S-odmikalom po metodi odzivne povrsine. Strojniski Vestnik-Journal of Mechanical Engineering, 2016; 62.9: 503-511.

[6] Hecht Basch, R., Fash, J., Hasson, R., et al. Initial dynamometer and laboratory evaluations of thermally sprayed aluminium brake disc. Barton D, Earl S, Brakes, 2000; 11-12.

[7] Sergent, N., Tirovic, M. and Voveris, J., Design optimization of an opposed piston brake caliper. Engineering Optimization, 2014; 46.11: 1520-1537.

[8] Mathur, A. and Kurna, S. Weight optimization of Axle Beam using Optistruct, In: Altair Technology Conference, India, 2015.

[9] Topac, M. M. and Atak, M. Optimal design of a rigid front axle beam for trucks, In: 1st International Mediterranean Science and Engineering Congress (IMSEC 2016), Çukurova University, Congress Center, Adana/Turkey, October 26-28 2016, paper no. 453.

[10] Topac, M. M., Kuralay, N. S. and Bahar, I. Mass and Stress Optimisation of a Multi-Purpose Vehicle Front Axle Differential Housing For Various Driving Conditions, Duzce University Journal of Science \& Technology, 2016; 4: 501-513.

[11] Topac, M. M., Bahar, E., Kaplan, A., et al. Design of a lower wishbone for a military vehicle independent front suspension using topology optimization. In IDEFIS 2017: 2nd International Defence Industry Symposium, 2017, pp.333-342.

[12] Yucel, U., Yilmaz, B., Guleryuz, I. C., et al. A back-plate weight optimization of a heavy-duty s-cam drum brake, In: International Mechanical Engineering and Technologies Conference Proceedings (MECHATECH'16), May 17-18 2016, Istanbul/Turkey, pp.218-235.

[13] Zhang, Y., Zhang, H., and Lu, C. Study on parameter optimization design of drum brake based on hybrid cellular multiobjective genetic algorithm. Mathematical Problems in Engineering, 2012; 734193.

[14] Ragothaman, G., Krishnan, R. A., Balamurugan, A., et al.
Design and Analysis of S-Camshaft And Torque Plate, International Journal of Pure and Applied Mathematics, 2018; 119.12: 13515-13522.

[15] Kuralay, N. S. Motorlu Taşıtlar; Temel ve Tasarım Esasları, Yapı Elemanları, Izmir: TMMOB Makina Mühendisleri Odas1, 2008. (In Turkish)

[16] Johnsen, S. Structural topology optimization: basic theory, methods and applications. MSc Thesis, Institutt for produktutvikling og materialer, 2013.

[17] Navarrina, F., Muiños, I., Colominas, I., et al. Topology optimization of structures: a minimum weight approach with stress constraints. Advances in Engineering Software, 2005; 36.9: 599-606.

[18] Bakhtiary, N., Allinger, P., Friedrich, M., et al. A new approach for sizing, shape and topology optimization. In: SAE international congress and exposition, Detroit, Michigan, USA, February 26-29 1996, 745-761.

[19] Bendøse, M. P. and Sigmund, O. Topology Optimization: Theory, Methods and Applications. ISBN: 3-540-42992-1. 2003. 